\title{
Oculomotor Nerve Palsy After Influenza Vaccine in Inflammatory Bowel Disease
}

\author{
Rajesh Essrani $^{1}$, Rajesh K. Essrani ${ }^{2}$, Shehriyar Mehershahi ${ }^{2}$, Arjun K. Lohana ${ }^{3}$, Anuraj Sudhakaran ${ }^{4}$ \\ 1. Internal Medicine, Lehigh Valley Health Network, Allentown, USA 2. Internal Medicine, Bronxcare Health System, \\ Bronx, USA 3. Internal Medicine, Liaquat University of Medical and Health Science, Hyderabad, PAK 4. Internal \\ Medicine, Geisinger Medical Center, Danville, USA
}

Corresponding author: Rajesh Essrani, raj1_essrani@hotmail.com

\begin{abstract}
Influenza and pneumococcal vaccines are recommended in inflammatory bowel disease patients. Several neurologic complications have been reported after influenza vaccines, such as Guillain-Barre syndrome, chronic inflammatory demyelinating polyneuropathy, and acute disseminated encephalomyelitis; however, rarely, oculomotor palsy will occur. We report the case of a 23-year-old male with a past medical history of ulcerative colitis on sulfasalazine who presented to the hospital with a complaint of blurry vision five days after an influenza vaccine. Most of the possible causes of oculomotor nerve palsy, such as stroke, intracranial space-occupying lesions, aneurysms, and infections, were ruled out by history, physical exam, blood work, and imaging studies, thus leading to the influenza vaccine as the most likely cause.
\end{abstract}

Received 12/10/2018

Review began 12/13/2018

Review ended 12/20/2018

Published 12/21/2018

๑) Copyright 2018

Essrani et al. This is an open access article distributed under the terms of the Creative Commons Attribution License CC-BY 3.0., which permits unrestricted use, distribution, and reproduction in any medium, provided the original author and source are credited.
Categories: Internal Medicine, Gastroenterology, Public Health

Keywords: inflammatory bowel disease (ibd), influenza, oculomotor nerve palsy

\section{Introduction}

The United States Advisory Committee on Immunization Practices (ACIP) recommends an influenza vaccination for all individuals six months of age and older. Patients with inflammatory bowel disease (IBD) are at high risk for infections due to their underlying disease, malnutrition, surgery, or immunosuppressive medications [1-2]. Regardless of immunosuppression, all patients with IBD should be vaccinated for influenza and pneumococcal infection.

Influenza vaccine is very safe and widely recommended to prevent influenza virus infection complications in high-risk populations [3]. It is an inactivated vaccine with a few side effects, such as soreness at the vaccination site, fever, malaise, and myalgia. Several neurologic complications have been reported after influenza vaccines, such as Guillain-Barre syndrome [4], chronic inflammatory demyelinating polyneuropathy [5], acute disseminated encephalomyelitis [6], acute transverse myelitis [7], optic neuritis [8], cerebellar ataxia [9], giant cell arteritis [10], hypoglossal palsy [11], and vasculitis ulnar mononeuropathy, but rarely oculomotor palsy will occur.

We present a rare case report of transient oculomotor palsy after an influenza vaccine in an inflammatory bowel disease patient.

\section{Case Presentation}

A 23-year-old male with a past medical history of ulcerative colitis on sulfasalazine presented to the hospital with a complaint of blurry vision five days after an influenza vaccine. He had no medical history of diabetes mellitus, hypertension, glucose intolerance, systemic vasculitis, hyperlipidemia, smoking, or obesity. He denied smoking cigarettes, drinking alcohol, using intravenous drugs, and was sexually active with one female partner only. He had no significant family history of neurological disorders.

On a general physical exam, his blood pressure was 122/67. The ophthalmic exam showed a dilated pupil in the right eye, mild ptosis, and diplopia with reduced adduction, elevation, and depression of the right eye but abduction and intorsion were fine. No abnormality was detected in other cranial nerve exams. Neurological and other system examinations were normal.

On blood work, the complete blood count, comprehensive metabolic panel, erythrocyte sedimentation rate, lipid panel, and hemoglobin a1c (HbA1c) were unremarkable. Imaging of the brain that included computed tomography (CT) of the head without contrast, magnetic resonance imaging (MRI) of the brain with and without intravenous (IV) contrast, and magnetic resonance angiography (MRA) of the head and neck with and without IV contrast were unremarkable. The cerebrospinal fluid analysis was normal. He was treated conservatively with lubricating eye drops, and his symptoms resolved in two weeks.

\section{Discussion}


Influenza vaccine is recommended annually in IBD patients. The influenza vaccine is generally well tolerated with only a few local injection side effects and no documented effects or flare-up of IBD activity [12].

A third cranial nerve palsy can result from lesions anywhere along its path between the oculomotor nucleus in the midbrain and the extraocular muscles within the orbit. It can be complete or incomplete depending on pupillary involvement. Complete nerve palsy presents with an unreactive pupil, paralysis of elevation, adduction, and depression. The eye rests in a position of slight depression, abduction, and intorsion "down and out" [13]. An aneurysm of the posterior communicating artery leads to complete paralysis of cranial nerve (CN) III as parasympathetic fibers run in the periphery of the nerve. Incomplete palsy has pupil sparing, and it is usually caused by nerve ischemia due to hypertension, obesity, and smoking [14-16].

Most of the possible causes, including stroke, intracranial space-occupying lesions, aneurysms, and infections, were ruled out by history, physical examination, blood work, and imaging studies. The fact that this happened immediately after an influenza vaccination makes this a plausible cause, and the rapid improvement of the symptoms in our patient supports the rationale of demyelination for the pathogenesis of transient nerve palsy.

There have been only two case reports of CN III palsy post-influenza vaccine in the literature and only one in an IBD patient [17-18]. Underreporting may be due to the mild and transient nature of the symptoms.

\section{Conclusions}

Influenza is an inactivated vaccine with only a few side effects, like soreness at the vaccination site, fever, malaise, myalgia, and rarely, neurological complications, such as an oculomotor palsy. The ACIP recommends an influenza vaccination for all individuals six months of age and older. It is important to mention that side effects do not outweigh the beneficial effects of the vaccine.

\section{Additional Information \\ Disclosures}

Human subjects: Consent was obtained by all participants in this study. Conflicts of interest: In compliance with the ICMJE uniform disclosure form, all authors declare the following: Payment/services info: All authors have declared that no financial support was received from any organization for the submitted work. Financial relationships: All authors have declared that they have no financial relationships at present or within the previous three years with any organizations that might have an interest in the submitted work. Other relationships: All authors have declared that there are no other relationships or activities that could appear to have influenced the submitted work.

\section{References}

1. Rahier JF, Yazdanpanah Y, Colombel JF, Travis S: The European (ECCO) Consensus on infection in IBD: what does it change for the clinician?. Gut. 2009, 58:1313-15. 10.1136/gut.2008.175950

2. Long MD, Martin C, Sandler RS, Kappelman MD: Increased risk of pneumonia among patients with inflammatory bowel disease. Am J Gastroenterol. 2013, 108:240-48. 10.1038/ajg.2012.406

3. Ahmed F, Singleton JA, Franks AL: Clinical practice. Influenza vaccination for healthy young adults . N Engl J Med. 2001, 345:1543-47. 10.1056/NEJMcp011924

4. Haber P, DeStefano F, Angulo FJ, Iskander J, Shadomy SV, Weintraub E, Chen RT: Guillain-Barre syndrome following influenza vaccination. JAMA. 2004, 292:2478-81. 10.1001/jama.292.20.2478

5. Kelkar P: Chronic inflammatory demyelinating polyneuropathy (CIDP) with rapid progression after influenza vaccination: a report of three cases. J Clin Neuromuscul Dis. 2006, 8:20-25. 10.1097/01.cnd.0000245215.86174.79

6. Saito H, Endo M, Takase S, Itahara K: Acute disseminated encephalomyelitis after influenza vaccination . Arch Neurol. 1980, 37:564-66. 10.1001/archneur.1980.00500580060009

7. Graus F, Ribalta T, Ribera G, Condom E, Nadal P: Acute necrotic myelopathy associated with influenza vaccination. Lancet. 1987, 1:1311-12. 10.1016/s0140-6736(87)90560-5

8. Hull TP, Bates JH: Optic neuritis after influenza vaccination. Am J Ophthalmol. 1997, 124:703-704. 10.1016/s0002-9394(14)70918-3

9. Saito H, Yanagisawa T: Acute cerebellar ataxia after influenza vaccination with recurrence and marked cerebellar atrophy. Tohoku J Exp Med. 1989, 158:95-103. 10.1620/tjem.158.95

10. Perez C, Loza E, Tinture T: Giant cell arteritis after influenza vaccination. Arch Intern Med. 2000, 160:267787.

11. Felix JK, Schwartz RH, Myers GJ: Isolated hypoglossal nerve paralysis following influenza vaccination. Am J Dis Child. 1976, 130:82-83. 10.1001/archpedi.1976.02120020084018

12. Benchimol EI, Hawken S, Kwong JC, Wilson K: Safety and utilization of influenza immunization in children with inflammatory bowel disease. Pediatrics. 2013, 131 :e1811-20. 10.1542/peds.2012-3567

13. Brazis PW, Lee AG: Binocular vertical diplopia. Mayo Clin Proc. 1998, 73:55-66. 10.1016/s00256196(11)63620-3

14. Asbury AK, Aldredge H, Hershberg R, Fisher CM: Oculomotor palsy in diabetes mellitus: a clinicopathological study. Brain. 1970, 93:555-66. 10.1093/brain/93.3.555 


\section{Cureus}

15. Teuscher AU, Meienberg O: Ischaemic oculomotor nerve palsy. Clinical features and vascular risk factors in 23 patients. J Neurol. 1985, 232:144-49. 10.1007/bf00313889

16. Jacobson DM, McCanna TD, Layde PM: Risk factors for ischemic ocular motor nerve palsies . Arch Ophthalmol. 1994, 112:961-66. 10.1001/archopht.1994.01090190109029

17. de Almeida DF, Teodoro AT, Radaeli Rde F: Transient oculomotor palsy after influenza vaccination: short report. ISRN Neurol. 2011, 2011:849757. 10.5402/2011/849757

18. Rouby F, Kheloufi F, Micallef J: Third nerve palsy after influenza vaccination in inflammatory bowel disease (IBD). Therapie. 2017, 72:695-97. 10.1016/j.therap.2017.04.005 